\title{
NUMERICAL ANALYSIS OF FLAT SLABS WITH SPHERICAL VOIDS SUBJECTED TO SHEAR FORCE
}

\author{
M. Bindea ${ }^{\text {a, } * \text {, Claudia Maria Chezan }}{ }^{\text {a }}$, A. Puskas ${ }^{\text {a }}$ \\ Technical University of Cluj-Napoca, Faculty of Civil Engineering, 28 Memorandumului Str., 400114, Cluj-Napoca, Romania, \\ e-mail: mihai.bindea@dst.utcluj.ro
}

Received: 14.03.2015 / Accepted: 01.04.2015 / Revised: 28.04.2015 / Available online: 31.05.2015

DOI: $10.1515 /$ jaes-2015-0001

KEY WORDS: FE Analysis, Concrete Flat Slabs, Spherical Voids, Shear Strength

\begin{abstract}
:
Full flat slabs can be enhanced by using spherical voids to replace the unemployed concrete from the core part of the slab. Therefore we get low self-weighted slabs that can reach a high range of spans, a low material consumption compared to classical solutions used so far. On the other hand, the upsides of these slabs pale against the insecurity in design stage about their punching and shear force behaviour. In this paper it is presented a parametric study about shear force behaviour of flat slabs with spherical voids used in standard condition service. The study was made using the Atena 3D finit element design software, starting form a numerical model gauged on experimental results on real models - scale 1:1. Based on these lab results, the model's validation was made by overlapping the load - displacement experimental curves on the curves yielded from numerical analyses. The results indicate that under a longitudinal reinforcement rate of lower than $0.50 \%$, flat slabs with spherical voids don't fail to shear force and over this value the capable shear force decreases in comparison with solid slabs, as the reinforcement rate increases.
\end{abstract}

\section{INTRODUCTION}

\subsection{General considerations}

Introducing the plastic balls (spheres or flattened rotationally symmetrical void formers) to replace and therefore eliminate the concrete in the middle strip of a full flat slab, which does not contribute to its structural performance, one obtains a hollow flat slab that span in two directions (after www.bubbledeck.com viewed at 14.02.2015, and Albrecht, 2012). The advantages thus obtained are many: economic savings, longer spans between supports, faster construction time and enviromantally friendly. However, despite these advantages, some uncertainties concerning the shear strength are expected. In these conditions the question is to what degree the spherical hollow cores influence the shear bearing capacity of the slab in comparison with the classical solutions of flat slabs. Or, more specifically, up to what loading level, the slab behaviour at shear force is affected by the spherical hollow cores, knowing the fact that the reinforced concrete flat slabs, besides the supports zones, are in general in a moderate stress regime (Bindea, 2013a). If the punching shear could easily be resolved by eliminating the plastic balls from the areas around columns still remains an issue to establish the dimensions for the perimeter of solid slab.
Considering, from the punching shear provisions (Kiss and Onet, 2008), the first control perimeter $u l=2 d$ as the perimeter of solid slab, the check of shear stress at control perimeter is in a direct relation with the shear strength of the hollow flat slab. So, it is important to establish the limits in which the shear strength of the hollow flat slab could be considered same as for the full slab. Concerning the load bearing behaviour of biaxial hollow slabs, numerical and experimental studies has been reported in our country and abroad, but there wasn't considered all the loading level range (Schnellenbach-Held \& Pfeffer, 2002, SchnellenbachHeld \& Aldejohann, 2005; Abramski 2010; Calin, 2010).

\subsection{Experimental tests}

The present study has the strating point in the laboratory where we conducted experimental tests on four slabs with spherical voids (bubbledeck slab system) and a normal slab, subjected to shear force. The test was made on four point bending. The reinforcing percentage and the shear arm $-\mathrm{a} / \mathrm{d}$ ratio has varied. The failure of low reinforcing percentage elements occured during bending. As noticed in figure 1, the DG3 slab showed shear force failure by crushing of

\footnotetext{
* Corresponding author.
} 
concrete strut between bearings and load application points (Bindea, 2013b).

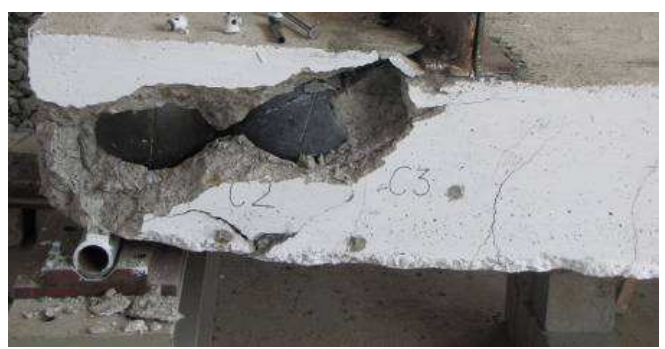

Figure 1. Failure at shear force - DG3 slab

\section{NUMERICAL MODEL}

\subsection{Constitutive models for concrete and reinforcement}

In order to achieve numerical analysis, the ATENA 3D (Advance Tool for Engineering Nonlinear Analysis) nonlinear design software was used. It is developed by Cervenka Consulting Company. The program is used with success especially for simulating the reinforced concrete structures behaviour (Cervenka 2011). Concrete modelling in ATENA3D is based on a tension cracking model mixed with a compression plastic range model, which can handle the increased deformation capacity of concrete under triaxial compression (Papanikolaou \& Kappos, 2007). Both models use "return mapping" type algorythm for integrating component equations (Cervenka \& Papanikolaou, 2008).

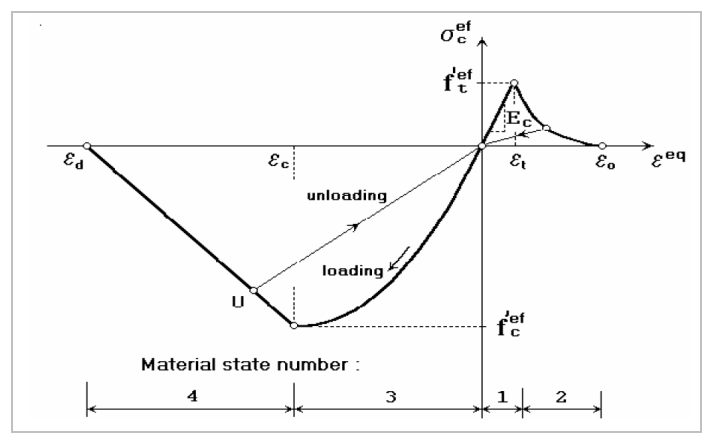

Figure 2. Uniaxial stress - strain law (Cervenka, 2012)

The component model "CC3NonLinCementious 2User" has been chosen, defined by the uniaxial stress - strain law (Figure 2) and by a biaxial failure function presented in Figure 3.

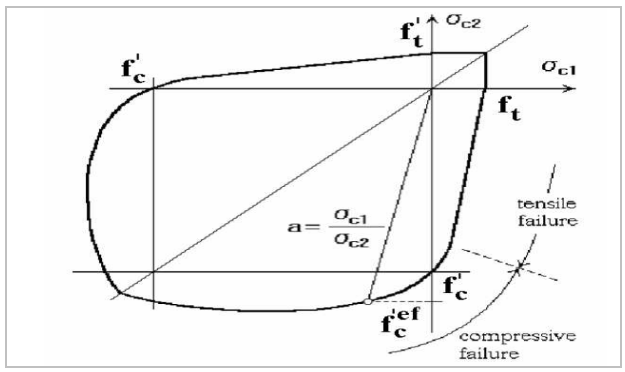

Figure 3. Biaxial failure function for concrete (Cervenka, 2012)
Using this component model for concrete allows us to use the material curves determined by lab experiments. Consequently, in order to define the compression concrete there was initiated a sigma - epsilon variation diagram (Figure 4), assigned/ traced by 20 points from the experimental curve.

In order to model the concrete tensile behaviour there was introduced a linear sigma - epsilon diagram, defined by 3 points determined according to the values of tensile strength and elasticity compression modulus of concrete (obtained in laboratory by split tests on $150 \mathrm{~mm}$ cubes and compression tests on 100 x 100-300 mm prisms, conform RILEM 1994).

The behaviour curve for steel reinforcement (sigma epsilon) was defined through 3 points extracted from the lab experiments curves.

The steel sections used for loading and support of the elements were considered to be made of an ideal elastic material, in order to avoid errors because of local plasticity in higher stress areas.

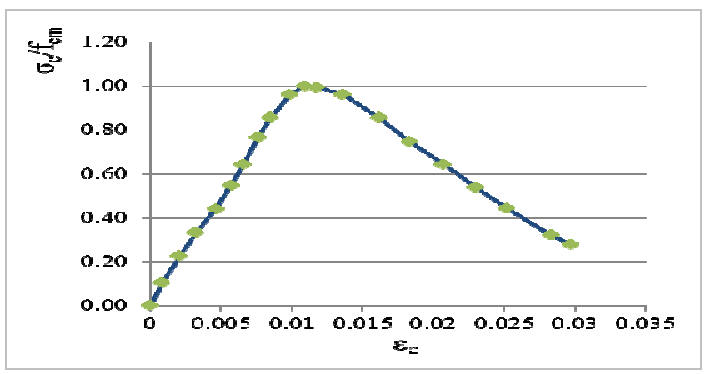

Figure 4. Sigma - epsilon curve for concrete in compression

\subsection{The finite elements and mesh size}

The discretization of the concrete and steel sections was made in "CCIsoTetra" tetraedric volumetric finite elements. These finite elements display a capability of nonlinear behaviour and count no more than 10 integration nodes. The reinforcement was modelled as independent truss bars. The geometry of finite elements is shown in Figure 5.

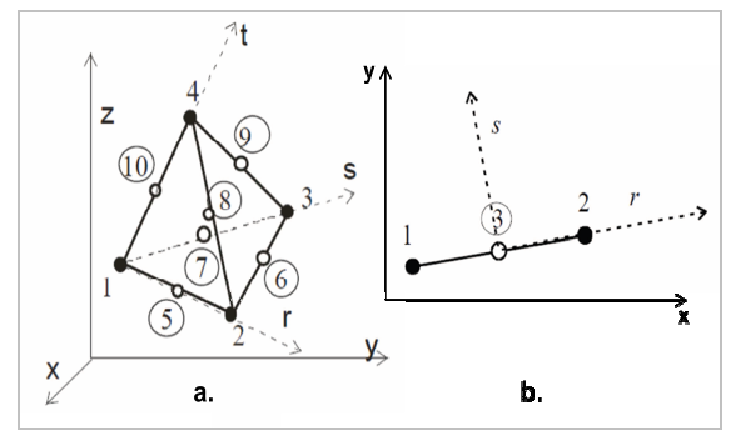

Figure 5. Geometry of finite elements (Cervenka, 2012)

In order to assign the finite element mesh, there were a number of several similar analyses (the mesh dimension varied from $6 \mathrm{~cm}$ to $10 \mathrm{~cm}$ ). Following these tests it was 
able to establish the finite element mesh for $8 \mathrm{~cm}$, based on the accuracy and precision of the results.

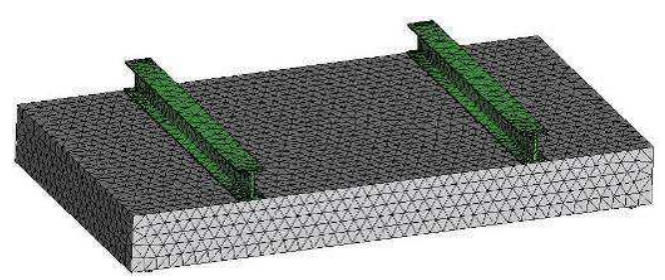

Figure 6. Numerical model with meshsize $=8 \mathrm{~cm}$

Being that the "bubbledeck" reinforcement models were made with steel mesh for both sides of the elements, there was considered a strong liability between concrete and longitudinal reinforcement. The numerical model considered a perfect liability between concrete and longitudinal reinforcement.

\subsection{Validation of numerical model}

The theoretical model has taken into account the following mechanical characteristics:
- Elasticity modulus for concrete $\mathrm{E}_{\mathrm{cm}}[\mathrm{MPa}] 36800$
Compression strength for concrete $\mathrm{f}_{\mathrm{cm}}[\mathrm{MPa}] 46.86$
Tensile strength for concrete $\mathrm{f}_{\mathrm{ctm}}[\mathrm{MPa}] 3.62$
Poisson's coefficient for concrete 0.2
- Elasticity modulus for reinforcement $E_{s} \quad[\mathrm{MPa}]$ 200000
- Yield strength for reinforcement $f_{y}[\mathrm{MPa}] 462$
- Poisson's coefficient for reinforcement 0.3

Taking into account that the DG3 element failed at shear force, the calibration of the theoretical model was made in initial state according to this element and was eventually validated according to the DG4 flat slab with voids (longitudinal percentage ratio $\mathrm{p}=0.31 \%$ ). The comparison was made in terms of load - displacement curve, but also in terms of failure mode.

Thus the calibration of the numerical model with spherical voids was made in several steps, as follows:

\section{- calibration related to DG3 element:}

o variation of load implementation parameters,

o variation of tensile behaviour parameters of concrete,

○ influence of the discretization mesh size,

- model validation according to DG4 and DP1 (full slab) elements.

The tensile concrete behaviour sigma - epsilon was set based on experimental tensile average strength for concrete and experimental elasticity modulus. The value for ultimate tensile strain $\varepsilon_{\mathrm{tu}}$ was established using the curve reported by J.Y. Cho in 2006. The behaviour curve obtained by Cho was determined from experimental tests at biaxial tension on reinforced concrete models having the compression strength $41 \mathrm{Mpa}$, value that is close enough to the compression strength obtained for the concrete used in our experimental programme $\left(f_{\mathrm{cm}}=46 \mathrm{MPa}\right)$.

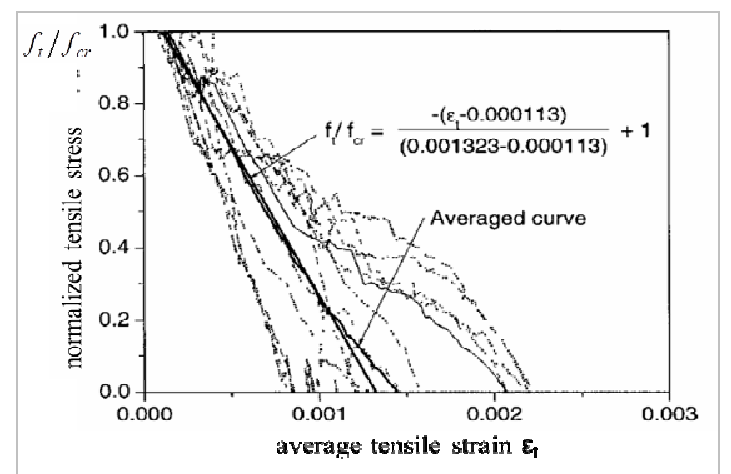

Figure 7. Average stress-strain relationship of concrete after crack occurrence (Cho, 2006)

The ultimate tensile strain $\left(\varepsilon_{\mathrm{tu}}=0.001323\right)$ was obtained using the expression form Figure 7 . This value was introduced in the behaviour curve for the concrete in tension, as it shown in Figure 8. Given that the tested elements were provided on both sides with welded reinforcing meshes we considered in the theoretical mode the tension stiffening coefficient by 0.4 as it is recommended in FibModelCode, 2010.

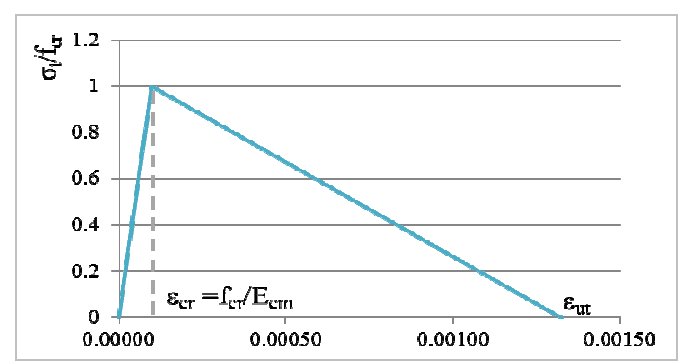

Figure 8. Sigma - epsilon curve for concrete in tension

As noticed in Figure 9, there are small differences regarding initial stiffness and maximal force and appending displacement. These differences appear due to the way the computation algorithm determines the moment of emergence and crack opening in tensile concrete.

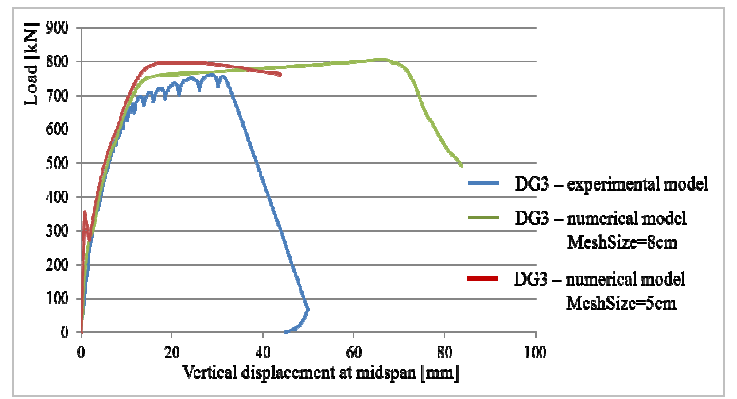

Figure 9. Variation of discretization mesh - numerical model MG3

According to Cervenka 2012, the cracking process divides into 3 stages (Figure 10). First stage ends while tensile strength in concrete is reached; the second one follows the cracking process until tension drops until total discharge, 
followed by the final stage, in which cracks keep on expanding without tensile tensions.

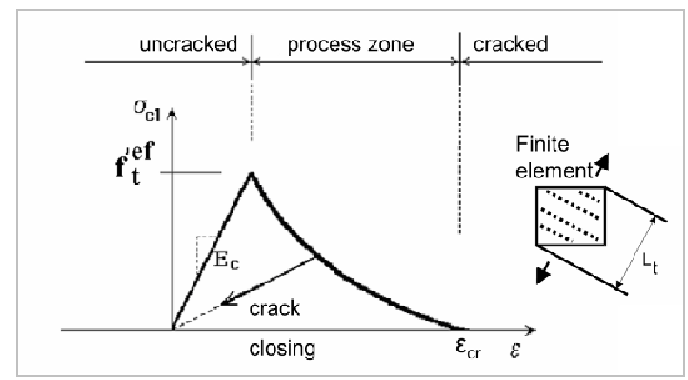

Figure 10. Cracking stages (Cervenka, 2012)

As reported by Cervenka 2012, the cracking width is determined in according to the size of the finite element and the crack openings are related to the cracking width, agreeably to the expression: where: $\varepsilon_{\text {cr }}$ is the crack opening strain, normal to the crack direction, yielded from cracking width after complete discharge of tensile tension.

Thus, as the size of finite elements decreases, the span between cracks also decreases, fact that leads to a higher stifness of the element, especially in spherical voids flat slabs, upon which it was noticed that, following experimental data, the gap between cracks is dependent on the transversal array of voids.

Thereby, as finite element size decreases, the gap between cracks decreases, leading to a higher stiffness of the element, especially in the case of spherical voids flats slabs those have shown during lab experiments that the distance between cracks is related to the presence of transversal arrays of voids.

There is no difference in failure mode, but the failure occurs also in the model that has a finer finite meshing mode, by inclined cracks between bearings and load application track, as shown in Figure 11.

$$
\mathrm{W}=\varepsilon_{\mathrm{cr}} \times \mathrm{L}_{\mathrm{t}}^{\prime},
$$

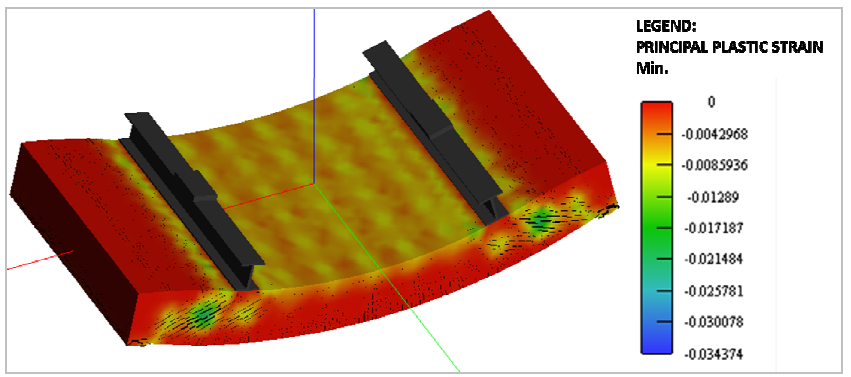

Figure 11. Failure mode - numerical model MG3 with meshsize $=5 \mathrm{~cm}$

A crack density arises, but in the same time also an alignment that imitates the direction and orientation of cracks yielded in the lab specimen.

Having the same material characteristic of MG3 model related to DG3 flat slab and changing only the reinforcement and a/d ratio, in order to obtain a good imitation of the experimental study of DG4 specimen, the behaviour diagram for MG4 numerical model was obtained - Figure 12 . One can notice that the numerical model displays a load - vertical displacement curve very close to the experiment, especially in the initial stage. The distinction concerning the ultimate load is under $10 \%$.

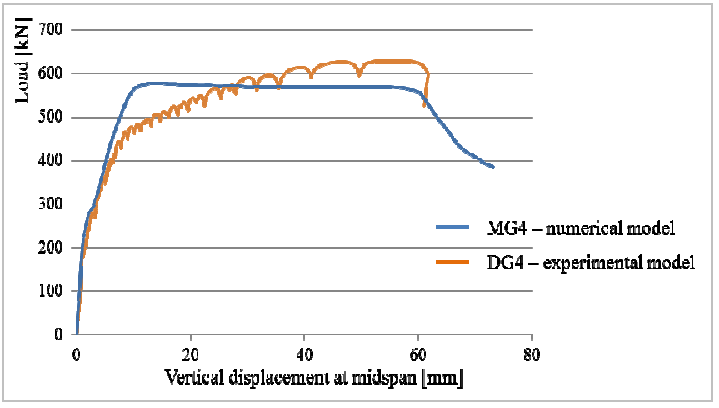

Figure 12. Verifying numerical model regarding slab DG4
In figure 13 it is shown the failure mode of the spherical void flat slab that has reinforcement ratio of $0.31 \%$ and a/d ratio of $\mathrm{a} / \mathrm{d}=1.8$. It is clear that failure occurred during normal cracks in core area of the slab. It shows that the cracks were emerged under the array of voids where the opening has reached the highest value.

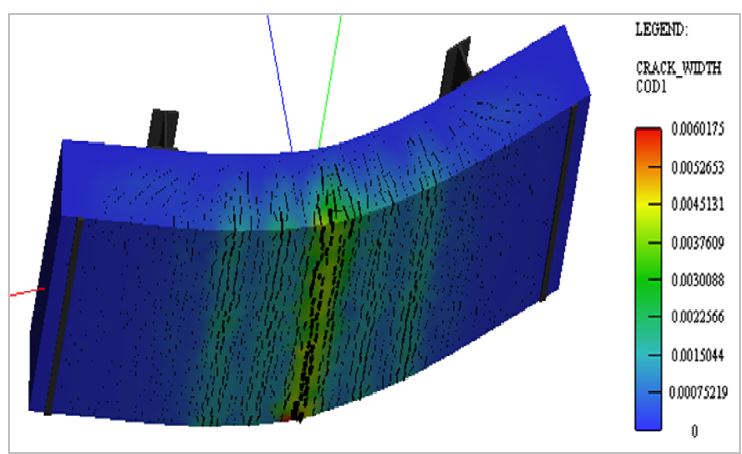

Figure 13. Failure mode - numerical model MG4

In figure 14 it is shown the F- $\Delta$ curve for the solid numerical model (the slab with no voids), overlapped by the curve of the solid slab DP1. One should notice that the differences are insignificant, both regarding the initial stiffness and also the maximum load value. 


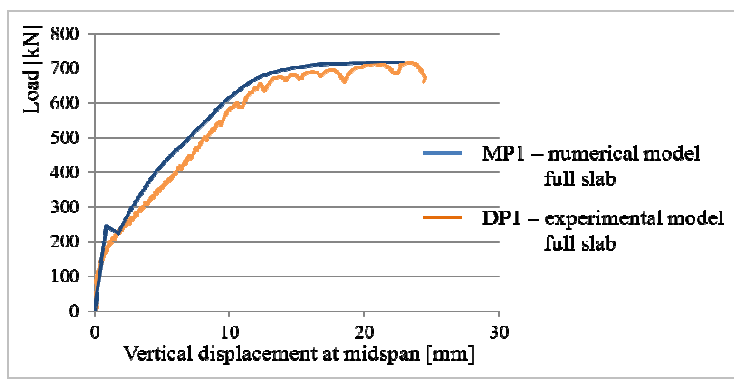

Figure 14. Verifying numerical model MG3 regarding solid slab

Taking into account that there are no major differences in behaviour regarding numerical simulation of lab experimental tests, the numerical model validation is considered a success.

Maintaining the mechanical characteristics determined above, we move on to the completion of parametric study.

\section{PARAMETRIC STUDY}

This study was made with the designation of supervising the behaviour of flat slabs with spherical voids and low steel ratio under shear force, exploring in wide range the influence of the studied parametres during the experimental programme.

Taking into account that the theoretical model was adjusted in terms of material properties, depending on the behaviour of tested specimens, within the parametric study the influence of concrete class and neither the void size were not aimed. The same mechanical characteristics of materials were followed, but the range for a/d ratio and steel ratio was extended.

For each set of parametres there were some analysis made, both for slabs with voids and solid slab with the same thickness.

In Figure 15 there are shown the load - displacement curves for model MG3 (theoretical model related to DG3 slab from the experimental study, reinforcing percentage $\mathrm{p}=0.52 \%$ ). The $\mathrm{a} / \mathrm{d}$ ratio ranges inside $1.8 \div 3.0$, both for specimens with voids (dotlined curves) and for the specimens without voids, but the same characteristics (continuous-lined curves).

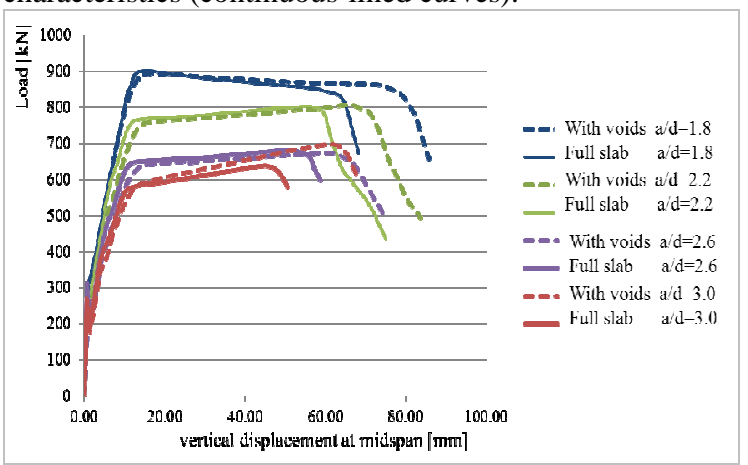

Figure 15. Variation of a/d ratio - numerical model MG3

$$
(p=0.52 \%)
$$

The load - displacement curves for MG4 model (theoretical model related to DG4 slab from the experimental study, reinforcing percentage $\mathrm{p}=0.31 \%$ ) are shown in Figure 16 . The shear arm varied as in MG3 model.

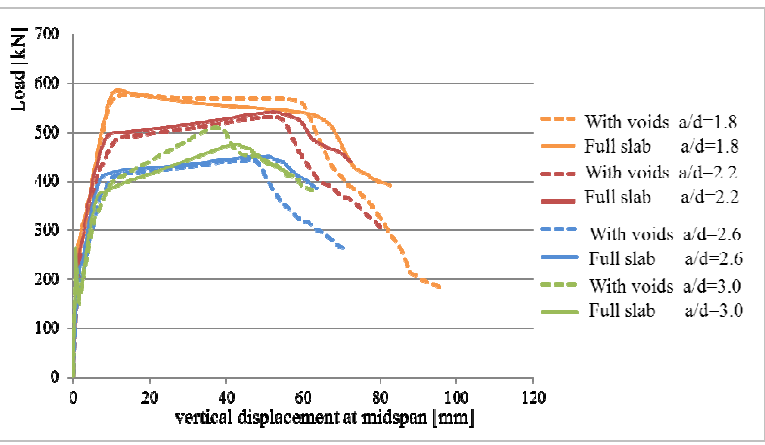

Figure 16. Variation of a/d ratio - numerical model MG4 $(\mathrm{p}=0.31 \%)$

Following the load - displacement curves, we can notice that the inequality of stiffness between the specimen with voids and the ones without voids decreases as the a/d ratio drops, also in the case of high steel ratio elements, the presence of voids increases significantly the ultimate dispacement. In $\mathrm{a} / \mathrm{d}=3.0$ ratio for both reinforcing ratios, an increase of ultimate failure load in flat slabs with voids compared to ones with no voids is noticed. This is due to the fact that, while increasing the a/d ratio, the inclined cracks become more present between bearings and load application points and the concrete plasticity is not focused on the height of compressed zone on the core section of the specimen.

There are no high differences between maximum shear force in models with voids, compared to those without voids. The worst case belongs to the flat slab with lomgitudinal reinforcement ratio of $0.52 \%$ and a/d ratio of 2.6 , whereas the shears force corresponded the solid slab outbalances by $4 \%$. All models with voids that have the reinforcement ratio of $0.52 \%$ failed at shear force and those with ratio of $0.31 \%$ failed at bending moment.

Also all models without voids (for all reinforcement ratios) failed at bending moment and the inclined cracks, from shear force, had values much lower than perpendicular ones in the central area of the slab.

Concerning the failure mode of specimens related to $\mathrm{a} / \mathrm{d}$ ratio, we noticed that, as the distance between load points and bearings increases, the inclined cracks are more obvious and appear much sooner than the yielding point of the element. This is the reason why the variation of the steel ratio was made for $\mathrm{a} / \mathrm{d}$ ratio of 3.0 .

It is presented in Figure 17 the F- $\Delta$ curves in relation to the variation of the reinforcing ratio. We can notice that the differences of stiffness and maximal load grow in value, as we increase the reinforcing ratio. Concerning the slabs with a steel ratio of up tu $0.52 \%$, the presence of voids does not negatively affect the maximum shear value. But as the reinforcing ratio increases over $0.52 \%$, the coresponding shear force of the specimens with voids will decrease, compared to the one coresponding solid slabs. The decrease 
(of $14 \%$ ) is more profound as the reinforcement ratio reaches the value $0.81 \%$.

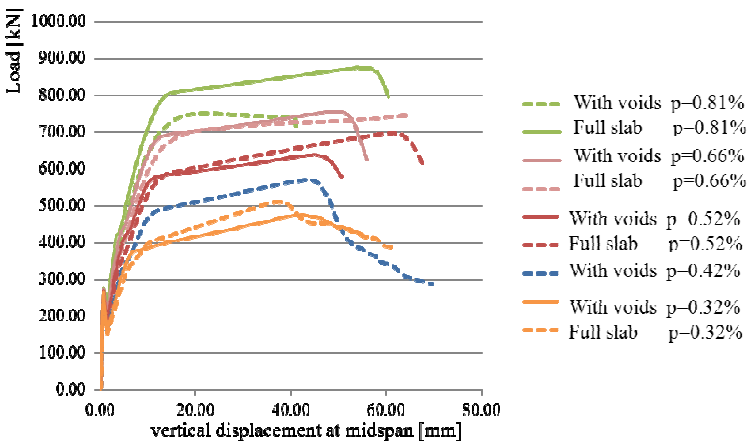

Figure 17. Variation of reinforcing percentage ratio ratio $\mathrm{a} / \mathrm{d}=3.0$

In Figure 18 it is presented the cracking state associated with the maximum stress value, view inside the numerical model of flat slab with sperical voids. The cracking plane of the inclined cracks can be noticed. The cracking plane intersects the spheres in their maximum diameter zone.

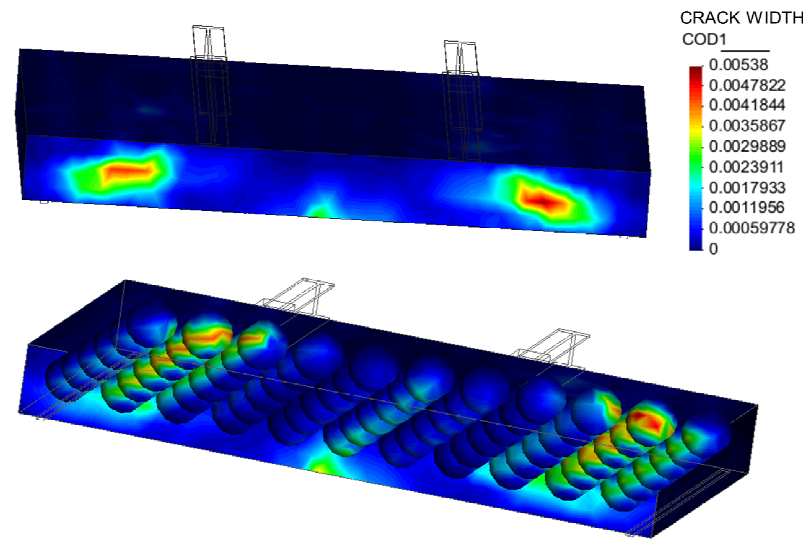

Figure 18. Cracking stage - numerical model MG3 of ratio

$$
\mathrm{a} / \mathrm{d}=3.0
$$

In all specimen with voids, even if failed at shear force, the failure occured after yielding point, but crack openings associated with serviceability limit state SLS $(\mathrm{w}=0.3 \mathrm{~mm})$ was achieved before the elements begin to yield (before reaching maximum load or horizontal curve on diagram F- $\Delta$ ).

\section{CONCLUSIONS}

In this parametric study there was a variation of the shear arm and reinforcing percentage. The mechanical characteristics of materials used and the geometry of the spherical voids remained constant throught the experiment. For each case of flat slab with spherical voids, there was a similar model without voids. The next conclusions have arised:

- The numerical model shows the behaviour of in-lab elements, from with initial stifness to failure mode, the differences between failure forces values are below $10 \%$.
- There is the confirmation of stifness reduction for bending of flat slabs with voids towards that of flat slabs without voids, along with the extension of reinforcing percentage and a/d ratio.

- In all $\mathrm{a} / \mathrm{d}$ ratios for flat slabs with spherical voids percentage of $0.52 \%$, failure occured during shear force, whilst for flat slabs with spherical voids percentage of $0.31 \%$, failure occured at bending moment.

- All slabs without voids collapsed at bending moment, no matter what the reinforcing percentage and shear arm was.

- $\quad$ By comparing the utimate values of shear force of flat slabs with spherical voids with those of flat slabs without voids concerning reinforcing percentage of up to $0.52 \%$, one should not notice remarkable differences $( \pm 5 \%)$.

- As reinforcing percentage rises, the ultimate shear force for flat slabs with spherical voids decrease from that of solid slabs.

Based on the numerical analysis results, one can conclude that flat slabs with spherical voids with reinforcing percentage of $0.5 \%$ don't display a very different behaviour for shear force compared to that of solid slabs of same thickness.

In slabs with reinforcing percentage between $0.50 \% \div$ $0.80 \%$, failure may occur through inclined cracking from shear force, even though ultimate shear force value don't differ much of that of maximum shear force for solid slabs of the same geometry, in which case failure occurs in normal cracks from bending. Thus, considering experimental values and the fact that numerical analysis confirm reaching the serviceability limit state of inclined cracks $(\mathrm{w}=0.3 \mathrm{~mm})$ before reaching yield point of longitudinal reinforcement, the bearing capacity for shear force in flat slabs with spherical voids can be considered conservative as being $60 \%$ of bearing capacity of reinforced concrete solid slabs.

\section{REFERENCES}

Albrecht C., Albert A., Pfeffer K., Schnell J., 2012. Design and construction of two-way spanning reinforced concrete slabs with flattened rotationally symmetrical void formers, Beton und Stahlbetonbau, No. 107, pp. 590-600, ISSN 0005-9900.

Abramski M., Albert A., Pfeffer K., Schnell J., 2010. Experimental and numerical investigations of the LoadBearing Behaviour of Reinforced Concrete Slabs Using Spherical Void Formers, Beton und Stahlbetonbau, No. 105, ISSN 0005-9900.

Bindea M., Moldovan D., Kiss Z., 2013a. Flat slabs with spherical voids. Part I: Prescriptions for flexural and shear design, Acta Technica Napocensis: Civil Engineering \& Architecture Vol. 56, No. 1, pp. 67-73

Bindea M., Zagon R., Kiss Z., 2013b. Flat slabs with spherical voids. Part II: Experimental tests concerning 
shear design, Acta Technica Napocensis: Civil Engineering \& Architecture Vol. 56, No. 1, pp. 74-81

Călin S., Asăvoaie C., Florea N., 2010 Issues for achieving an experimental model concerning bubble deck concrete slab with spherical gaps, Buletinul Institutului Politehnic din Iaşi, Tomul LVI (LX), Fasc. 2, Secţia CONSTRUCŢII.ARHITECTURA

Cervenka J., Papanikolaou V., 2008. Three dimensional combined fracture-plastic material model for concrete, International Journal of Plasticity, No. 20, pp. 2192-2220.

Cervenka J., 2011. Design of prestressed concrete nuclear containements assisted by numerical simulations, fib Symposium PRAGUE 2011, session 3-4: Modelling and Design.

Cervenka V., Jendele L., Cervenka J., 2012. ATENA Program Documentation Part 1 Theory, Prague.

Cho J. Y., Kim N. S., Cho N. S., Choun Y. S., 2006. Stress Strain Relationship of Reinforced Concrete Subjected to Biaxial Tension, ACI Structural Journal, V. 101, No. 2.

Kiss Z., Oneţ T., 2008. Proiectarea structurilor de beton după SR EN 1992-1, Editura Abel.

Papanikolaou V. K., Kappos A. J., 2007. Confinement sensitive plasticity constitutive model for concrete in triaxial compression, Interantional Journal of Solids and Structures 44 (2007) 7021-7048.

Schnellenbach-Held M., Aldejohann M., 2005. Zweiachsige Hohlkorperdecken in Theorie und Versuchen, BFT Betonwerk + Fertigteil-Technik, 10/2005, pp.50-59.

Schnellenbach-Held M., Pfeffer K., 2002. Punching behavior of biaxial hollow slabs" Cement and Concrete Composites, Volume 24, Issue 6, Pages 551-556.

*** CEB FIB Model Code 2010, Fédération Internationale du Béton, 2008, 2010.

*** RILEM, 1994. RILEM Technical Recomandations for the Testing and Use of Construction Materials, E\&FN Spon, St Edmundsbury Press, Great Britain: International Union of Testing and Use of Construction Materials.

*** www.bubbledeck.com viewed at 14.02.2015. 